\title{
The Long-Term Ecosystem Observatory: An Integrated Coastal Observatory
}

\author{
Oscar Schofield, Trisha Bergmann, Paul Bissett, J. Frederick Grassle, Dale B. Haidvogel, Josh Kohut, Mark Moline, \\ and Scott M. Glenn
}

\begin{abstract}
An integrated ocean observatory has been developed and operated in the coastal waters off the central coast of New Jersey, USA. One major goal for the Long-term Ecosystem Observatory (LEO) is to develop a real-time capability for rapid environmental assessment and physical/biological forecasting in coastal waters. To this end, observational data are collected from satellites, aircrafts, ships, fixed/relocatable moorings and autonomous underwater vehicles. The majority of the data are available in real-time allowing for adaptive sampling of episodic events and are assimilated into ocean forecast models. In this observationally rich environment, model forecast errors are dominated by uncertainties in the model physics or future boundary conditions rather than initial conditions. Therefore, ensemble forecasts with differing model parameterizations provide a unique opportunity for model refinement and validation. The system has been operated during three annual coastal predictive skill experiments from 1998 through 2000 . To illustrate the capabilities of the system, case studies on coastal upwelling and small-scale biological slicks will be discussed. This observatory is one part of the expanding network of ocean observatories that will form the basis of a national observation network. These regional efforts should be linked through satellite remote sensing and surface current radar systems. Data on the ocean interior will be provided from subsurface AUVs and moorings. The combined data should be available through a network of virtual labs capable of rapid data visualization and dissemination.
\end{abstract}

Index Terms-Forecasting, rapid environmental assessment.

\section{INTRODUCTION}

"The very few existing time-series stations paint a compelling picture of important oceanic changes in physics, chemistry and biology. Yet these stations capture the time domain at only a single point. New strategies for observing the appropriate spatial correlation are required."-Ocean Sciences at the New Millennium, Ocean Sciences Decadal Committee 2001.

A LTHOUGH the continental margin represents only about $8 \%$ of the surface area of the world's oceans, it represents a region that is disproportionately important to humans. For ex-

Manuscript received December 15, 2000; revised October 15, 2001. This work was supported in part by the Office of Naval Research under Grant N00014-97-0797 and Grant N0014-99-0196, in part by the National Ocean Partnership Program under Grant N00014-97-1-1019, in part by the National Science Foundation under Grant OCE-9314823 and in part by the National Undersea Research Program under Grant NA-76RU0165.

O. Schofield, T. Bergmann, J. F. Grassle, D. B. Haidvogel, J. Kohut and S. M. Glenn are with the Coastal Ocean Observation Laboratory, Institute of Marine and Coastal Sciences, Rutgers University, New Brunswick, NJ 08901 USA.

P. Bissett is with the Florida Environmental Research Institute, Tampa, FL 33611 USA.

M. Moline is with the Department of Biology, California Polytechnic State

University, San Luis Obsipo, CA 93407 USA.

Publisher Item Identifier S 0364-9059(02)03375-7. ample, despite its small area, the coastal ocean represents up to $30 \%$ of the total global ocean productivity and more then $90 \%$ of the world's fish catch [1]. The coastal ocean represents the major filter between the terrestrial and open oceans with the majority of the terrestrial nutrient inputs being trapped and remineralized on the continental margins [2], [3]. Evidence is mounting that human activity is altering nutrient patterns and food web structure [4]. These human-induced changes are likely to increase in the coming decades with the projected development along the world's coastlines. Despite this, research efforts often ignore the nearshore coastal waters due to the difficult operating conditions caused by numerous turbulent boundary layers and highly variable currents.

Effective management of our coastal resources will require physical/biological climatologies as well as the ability to nowcast and forecast events of interest. Climatologies derived from time series data are invaluable for determining relative trends as well as the magnitudes and duration of broad seasonal features (examples include regional hydrographic patterns, spring blooms, fish migration etc.). These long-term time series are rare in aquatic ecosystems, but where available (see California cooperative oceanic fisheries investigations [5], http://www-mlrg.ucsd.edu/calcofi.html, Hawaii Ocean Time Series [6], http://hahana.soest.hawaii.edu/hot/hot_jgofs.html, Bermuda Atlantic Time Series [7], http://www.bbsr.edu/cintoo/bats/bats.html) have provided fundamental insight into the ecosystem structure and function. Superimposed on the seasonal dynamics are numerous short duration events. These natural and man-made episodic events (such as upwelling, storms, pollution spills, etc.) represent features that are often critical to determining overall productivity and aquatic food web structure, yet are not effectively sampled using traditional approaches. The available climatologies do not provide the appropriate data to characterize episodic events and often have little value in studying and/or responding to them. Nowcast/forecast systems provide the key to characterizing these episodic events by providing guidance on when and how to utilize the available scientific assets. To develop a nowcast/forecast capability for coastal waters requires a mutliplatform sampling approach [8]-[11] combined with a suite of data assimilative models [12], [13].

Efforts over the last decade have resulted in the development of regional coastal ocean observatories. These observatories all differ in design and stage of development, but all provide a potential means to collect ocean time series databases and provide a mechanism to conduct detailed process studies on episodic events. As part of the national network of coastal observatories, 

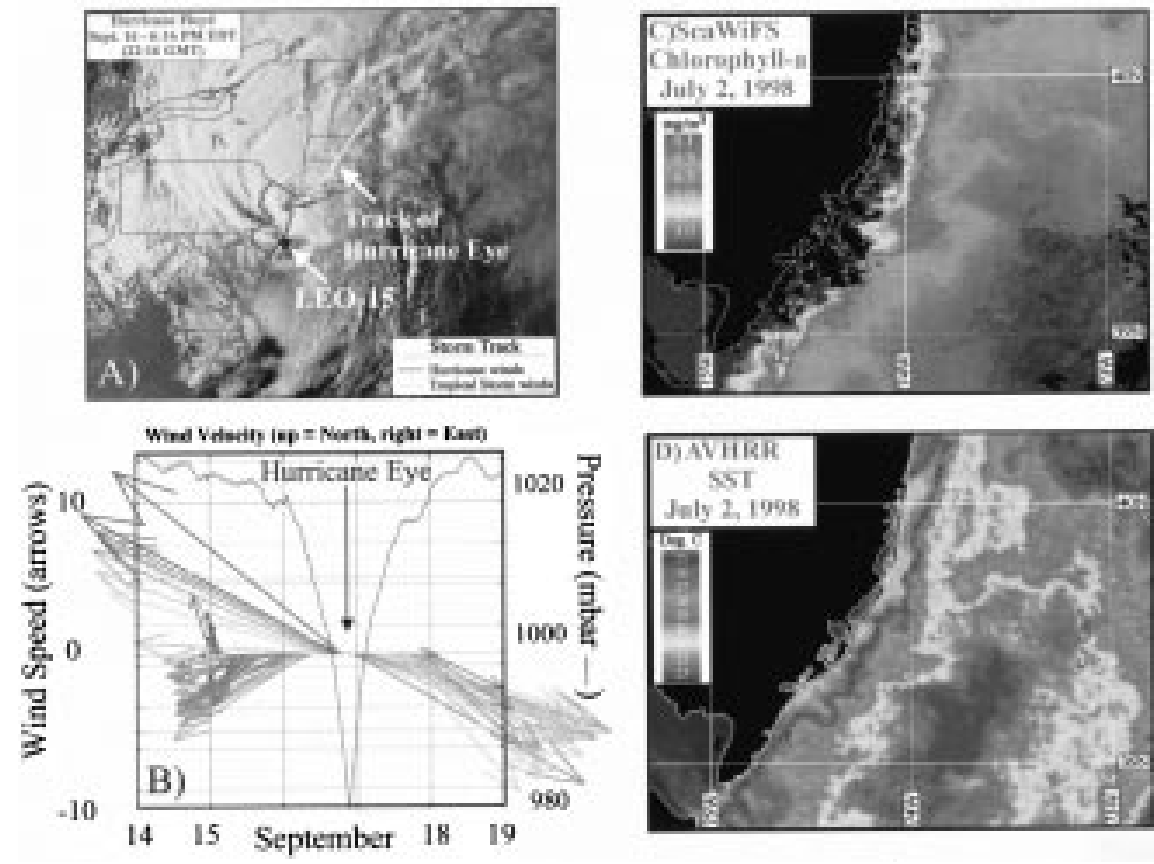

Fig. 1. Examples of standard MET and remote sensing products at the LEO site. (a) Location of the LEO site along the Eastern Seaboard. The track of Hurricane Floyd is denoted by a line and eye of the Floyd passed directly over the LEO field site. (b) Measured wind speed/direction and barometric pressure during Hurricane Floyd. (c) Satellite maps of chlorophyll $a$ as measured by the SEAWiFs ocean color satellite during upwelling in July 1998. (d) Sea surface temperature as measured by the AVHRR satellite during upwelling in July 1998.

the Long-term Ecosystem Observatory (LEO) was established in 1996. This manuscript will describe the current capabilities of LEO providing examples from a series of coastal ocean predictive skill experiments; furthermore we suggest how the regional observatories might be linked to form the foundation for a national coastal ocean observatory network.

\section{COMPONENTS OF THE LONG TERM ECOSYSTEM OBSERVATORY}

The LEO study area is located off the New Jersey coast in the middle Atlantic Bight [MAB; Fig. 1(a)] and is a coupled system where the data is assimilated into forecast models, which can then in turn be used to adjust the sampling patterns of the field assets. The LEO site has recently hosted a series of coastal predictive experiments (CPE). The first CPE in 1998 focused on improving nowcast accuracy via data assimilation. The second CPE in 1999 to focus on improving forecast accuracy via improved boundary forcing, characterizing the spatial and temporal scales of variability in inherent optical properties and developing alternative turbulent closure schemes for shallow coastal waters. The third CPE in summer 2000 used the expertise developed in 1998 and 1999 to hone rapid environmental assessment techniques in a $30 \mathrm{~km}$ x $30 \mathrm{~km}$ research space for physical/bio-optical adaptive sampling. Specific components to the LEO network include:

Meteorology: Meteorological data is key for forcing the ocean forecast model (see below) and LEO is outfitted for a full suite of local weather observations. A dedicated meteorological tower outfitted with a suite of sensors provides a standard set of local meteorological measurements [Fig. 1(b)]. The meteorological system includes a pair of acoustic atmospheric profilers that sample the lower $5000 \mathrm{~m}$ of the atmosphere for wind speed and direction. A key addition to LEO, was to complement on-shore weather measurements with an offshore Oceans Systems Inc. meteorological buoy located $15 \mathrm{~km}$ offshore. The buoy is outfitted for wind speed/direction, air temperature and barometric pressure. The ability to measure the spatial variability in the local weather is key for all observatories, as small-scale weather fluctuations at sea can be missed by land-based weather stations. This is critically important for model initialization and forcing.

The MET buoy also provides a platform and power for alternative instrument packages. For example, the buoy instrumentation included a hyperspectral $(<2 \mathrm{~nm}$ resolution) reflectance sensor consisting of in situ downward facing and above water upward facing spectrometers during the summer $2000 \mathrm{CPE}$. The buoy has a Freewave radio modem allowing two-way communication and automated data retrieval. Given the terrain of the local area, the marine field station provides an optimal location for radio-modem receivers that require line of sight with the assets at sea. Typically, radio modems have an effective range of almost $20 \mathrm{~km}$ offshore.

Remote Sensing: Remote sensing technologies are used to provide spatially extensive surface maps of both physical and biological properties. Ocean color [SeaWiFS, Fig. 1(c)] and thermal infrared [advanced very high resolution radiometer, Fig. 1(d)] sensors provide estimates of chlorophyll concentration and sea-surface temperature respectively, for data assimilation and model validation. The on-site satellite dish has been upgraded by SeaSpace Inc. to provide real-time data from the Chinese FY1-C ocean color satellite. The LEO site is a calibration site for the new generation of ocean color algorithms. The algorithms provide estimates of the inherent 

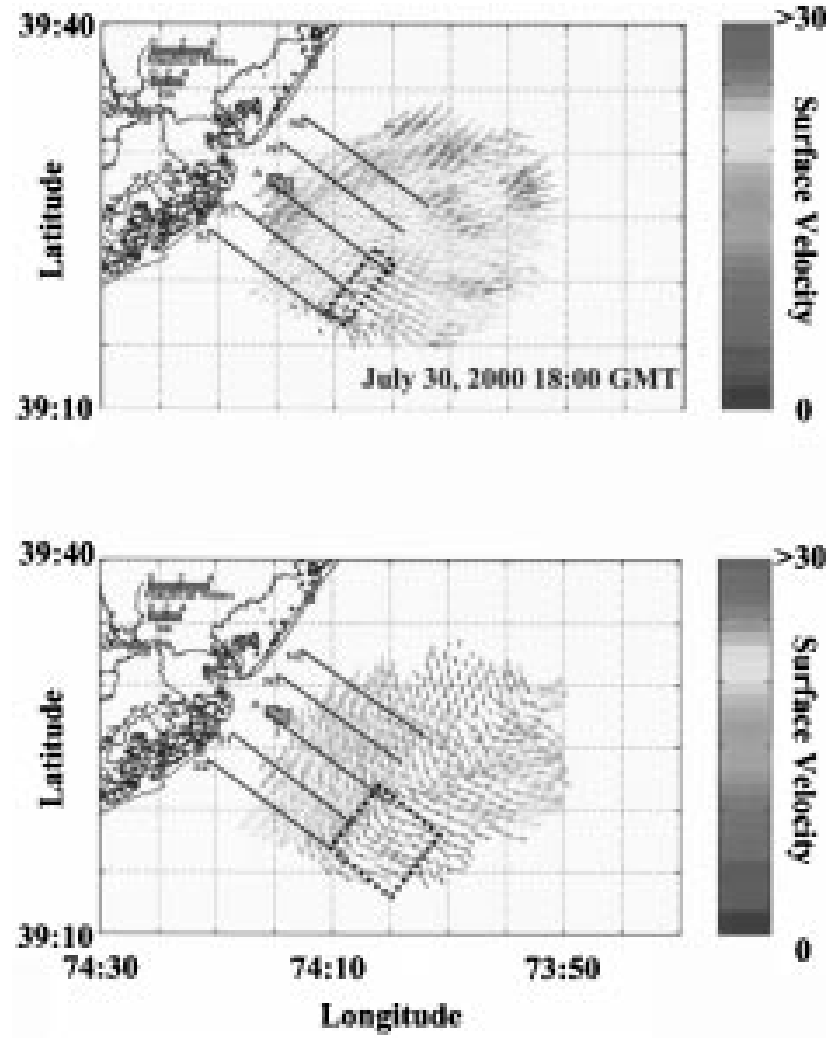

Fig. 2. Short-term tidal changes in currents as measured by CODAR imagery from 29 (Fig. 2a) and 30 July (Fig. 2b) during the summer CPE 2000. The changes in the current patterns associated with the tidal reversal impacted the presence of turbid convergence zones. The location and spatial extent of the convergence zone during the different tidal phases is delineated by the dotted-line box.

optical properties rather then empirically derived estimates of parameters such as chlorophyll $a$ or colored dissolved organic matter. The major advantage of this approach is that the inherent optical properties are easy to interpret and can be decomposed into the individual constituents which will be particularly useful for optically complex coastal waters. Future efforts will focus on receiving data from the growing international constellation of ocean color satellites. Delay-mode RADARSAT data is currently provided through NOAA-NESDIS.

Complementing the satellite imagery, the CODAR seasonde high-frequency radar system [14] measures real-time surface current fields (Fig. 2). Three different classes of CODAR are part of the network. An intermediate scale CODAR system that includes 2 beach antenna sites provides a surface current vector map every hour in near real-time. Each map extends about 50 $\mathrm{km}$ alongshore and $40 \mathrm{~km}$ offshore with a grid resolution of $1.5 \mathrm{~km}$. A suite of products such as divergence/convergence [Fig. 3(a)] and vorticity are derived from these CODAR maps. Efforts are currently underway to develop a second class of CODAR system that will eliminate the "blind spot" nearshore as seen in the CODAR surface current map in Fig. 2. This will be accomplished by placing two bistatic transmitters offshore and pairing them to existing beach sites. The signals from these offshore buoys will provide additional information of the surface velocity nearshore, allowing total surface currents to be extended onshore [Fig. 3(b)]. In addition to the intermediate scale system, three long-range CODAR sites have been installed along the New Jersey coast. These systems provide radial coverage over $190 \mathrm{~km}$ with a spatial resolution of 6 $\mathrm{km}$ [Fig. 3(c)]. One more long-range site will be installed in the fall of 2001. This four-site CODAR system will provide continuous surface current measurements for the entire MAB from the outer edge of Long Island to below Delaware Bay. The net result will be a nested continuous map of surface currents over the entire mid-Atlantic Bight with high-resolution measurements in the nearshore coastal waters at LEO.

Autonomous Nodes: To provide a flexible experimental platform for collecting continuous in situ time-series information a network of cabled instrumented nodes has been constructed (Fig. 4). The cabled network consists of two robotic nodes 10 $\mathrm{km}$ off the southern coast of New Jersey connected to shore via an electro fiber-optic cable. Each node has a vertical profiler outfitted with standard instrument package including a conductivity-temperature-depth (CTD) sensor, an optical backscatter sensor, a broadband radiometer and a chlorophyll fluorometer (FL) [Fig. 4(a)]. This instrument package is augmented with an upward looking acoustic doppler current profiler (ADCP). The LEO nodes are outfitted with a suite of "guest" ports providing power and real-time data telemetry to other instruments. A third optical node was constructed and tested during the 1999 summer experiment and operated continuously during the 2000 and 2001 experiments. This node was designed to provide a complete optical characterization of the water column, allowing for vicarious calibration of the new generation of ocean color satellites [Fig. 4(b)]. The optical node is equipped with a Wetlabs absorption-attenuation meter (ac-9), a Sequoia particle sizer (LISST), a bioluminescence bathyphotometer (BioLum), a Wetlabs volume scattering meter (VSF) and a HOBI labs Hydroscat-2 backscatter sensor (HS2).

Shipboard Adaptive Sampling: To provide a spatial extension around the cabled observatory in situ data is collected with ships and autonomous underwater vehicles (Fig. 5). The ships are generally divided into two categories. One category of vessels is designed to conduct rapid high-resolution surveys providing real-time data to the rest of the research fleet. These vessels are equipped with towed undulating systems. Typically, the instrumentation includes a surface-towed downward facing ADCP and a Guildline Inc. undulating towed CTD/Fluorometer/Optical Backscatter equipment package. Data from this vessel are beamed, via Freewave modem, back to shore in real-time to guide other ships to adjust sampling transects "on the fly". The second category of research vessel is outfitted with profiling instruments. Given the profiling nature of the instruments, these ships depend on the "survey" ships to provide data to optimize their sampling patterns. Currently, the profiling vessels are equipped with a wide suite of bio-optical instrumentation to characterize both the apparent and inherent optical properties. The bio-optical vessel is outfitted with a CTD, a Satlantic downward and upward facing ultraviolet/visible radiometer, a Wetlabs ac-9, a Wetlabs spectral fluorescence excitation/emission fluorometer (SaFire), a Satlantic hyperspectral radiometric buoy (TSRB), a HOBI labs six-wavelength backscatter sensor (HS-6), a bioluminescence bathyphotometer (BIOLUM) and an above water hyperspectral HOBI labs reflectance meter (HYDRORAD). 

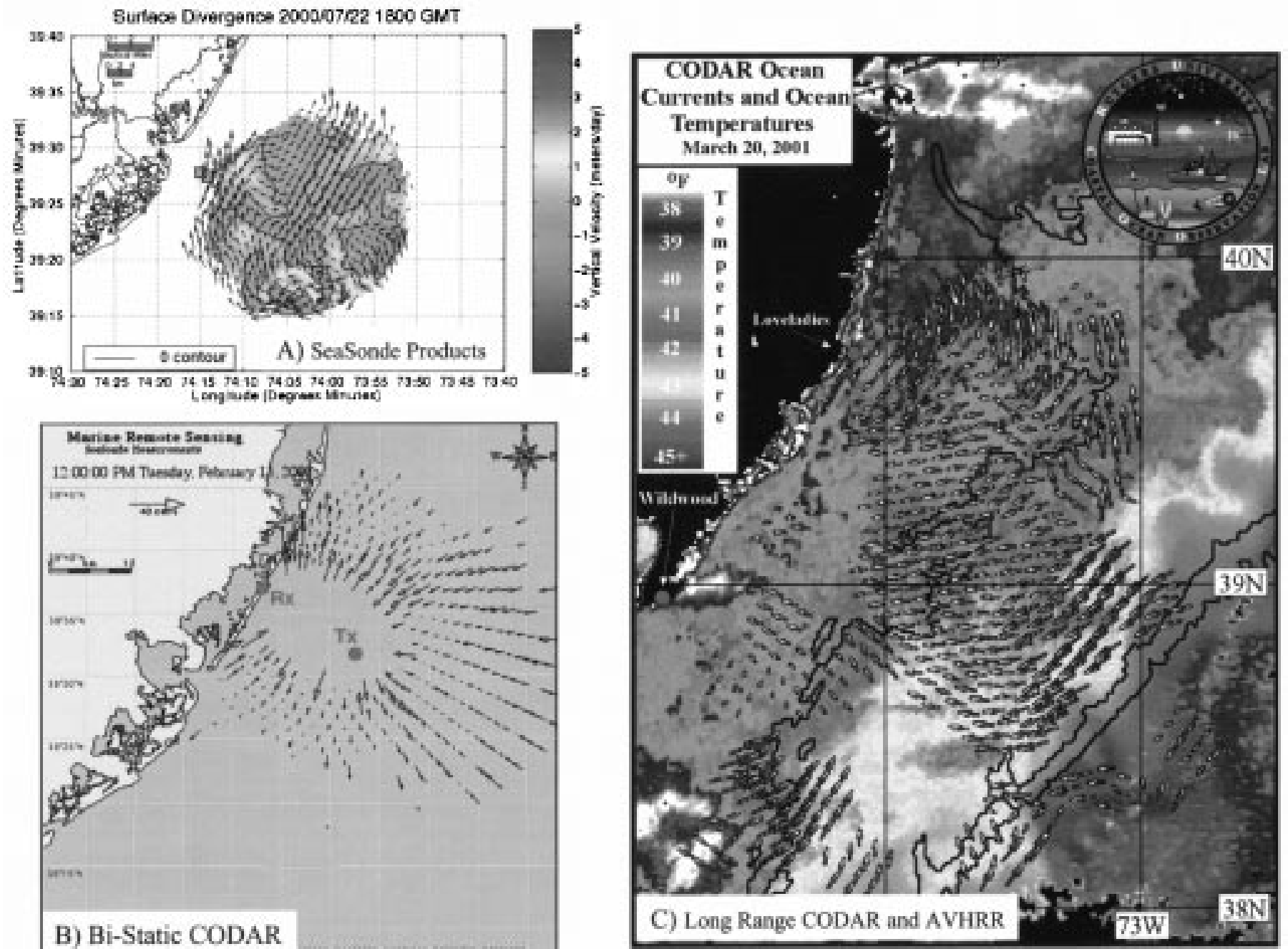

Fig. 3. The variety of measurements possible with the new generation of SeaSonde surface current radar systems. (a) A map of derived convergence/divergence from surface currents maps. This has allowed scientists in summer 2000 to track and adaptively sample biological features. (b) Demonstration of the BiStatic CODAR concept off the coast of New Jersey in winter 2001. The BiStatic CODAR pairs offshore bistatic transmitters to the existing beach sites. The signals from the offshore transmitter will provide additional information of the surface velocity nearshore, allowing surface currents to be extended onshore. (c) Long Range CODAR as measured by two sites along southern New Jersey. The range is close to $180 \mathrm{~km}$ offshore. Existing sites will be expanded by summer 2001 to provide complete coverage for the entire mid-Atlantic Bight. The measured surface currents are overlaid on a satellite sea surface temperature map. The flow of surface warm oligotrophic water up Hudson canyon is visible.

Autonomouss Underwater Vehicles: Two types of autonomous underwater vehicles (AUV) have been operated at LEO. The Remote Environmental Monitoring UnitS (REMUS) are propeller-driven AUVs that have been successfully operated at LEO-15 since 1997 [15]. REMUS Survey AUVs are modular, allowing instruments to be added for specific mission requirements. REMUS systems at LEO have been equipped with CTDs, upward/downward looking ADCPs, BIOLUMs and spectroradiometers. The navigation by the REMUS is facillitated by two-way communication with a series of transponders that are laid out along the AUV flight path.

The REMUS system was first sea tested at the LEO site in 1997. By 1998, the REMUS was outfitted with a CTD and ADCP and flew ten missions covering $261 \mathrm{~km}$. The data were available to the scientists about 4 months after collection. By 1999, the REMUS covered $366 \mathrm{~km}$ during eight missions and had data available upon return to the docks. This improved in summer 2000, when the REMUS flew 11 missions in an undu- lating manner covering $444 \mathrm{~km}$. Currently, the cost for using the REMUS to collect data averages about $\$ 160$ per $\mathrm{km}$. In contrast, collecting a comparable data set by leasing a small research vessel costs on average $\$ 40$ per $\mathrm{km}$. The cost per kilometer is calculated by dividing the total actual costs from research grants for salary, ship-time, supplies, etc. for supporting the REMUS and ship crews (collecting comparable data) during the CPE summer experiments. The costs associated with collecting AUV data will decrease dramatically in the coming years and during the summer 2001 the REMUS operations were transitioned from an engineering to a smaller science team. Transitions such as this will lead to a substantial decrease in the $\operatorname{cost} / \mathrm{km}$ for the REMUS.

The nonpropeller Webb Slocum Electric Glider [16] was deployed for ten days offshore Tuckerton, New Jersey for its first untethered open ocean flight during the 2000 summer experiment. The Glider is an autonomous vehicle, which moves up and down in the ocean by changing its buoyancy. Wings allow 


\section{A) 1997}
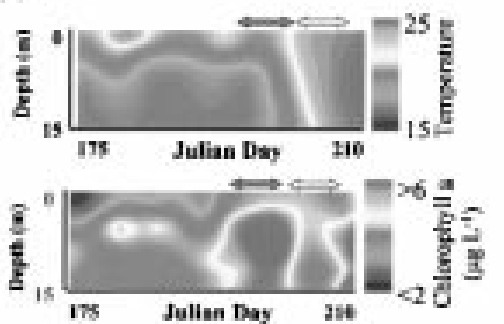

B) 1999

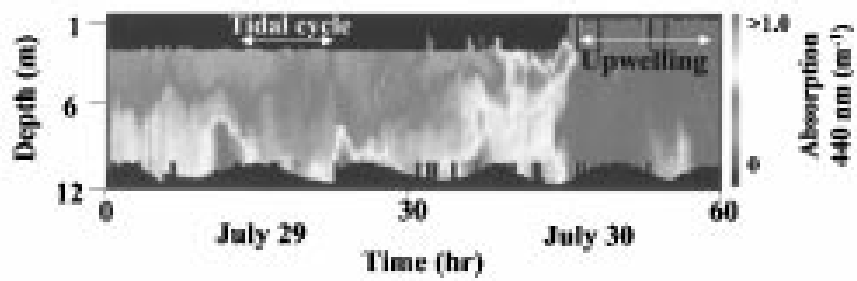

Fig. 4. Data examples from the in situ LEO cabled nodes. (a) Data collected during July 1997 illustrate the changes in water column temperature and phytoplankton concentrations (determined via chlorophyll $a$ fluorescence) during upwelling favorable winds (red arrow) and a North-Easter storm (yellow arrow). The interpolated figure represents 90 vertical profiles collected with the LEO node. (b) High-resolution time series collected during the 1999 summer experiment using a LEO node outfitted with a suite of optical sensors. The time series represents vertical profiles of absorption $\left(\mathrm{m}^{-1}\right)$ measured at $440 \mathrm{~nm}$ collected every $20 \mathrm{~min}$ for $60 \mathrm{~h}$. The optical variability associated with tidal cycles was swamped out by the increased turbidity that was associated with the initiation of upwelling.

steerable gliding, thus horizontal propulsion. This vehicle traces a saw-tooth profile, observing temperature, conductivity, etc. versus depth. At the surface, cellular telephone links are established allowing the glider to fix its position via GPS and communicate with scientists onshore. The Glider's nominal mission profile in the summer of 2000 consisted of a series of 2.5 min undulations with a surfacing interval every $45 \mathrm{~min}$. During the surface interval, a GPS position and data were transferred to shore and new mission profiles were downloaded with the Freewave modem. The Glider was recovered on Saturday, July 22. Over the 10-day period, the Glider collected 5,190 CTD casts with an average 45-min data delay without ever returning to the dock. The Glider, like the REMUS, is modular so instrument payloads can be customized for individual scientific needs.

Models: Observational data streams feed the regional data assimilative atmospheric and ocean model systems (Fig. 6). Typically, three- to four-day duration ocean forecasts are generated twice a week for a total of eight forecast cycles during each of the CPE experiments using the regional ocean modeling system (ROMS). The present version of ROMS runs on SMP-class parallel-computing platforms using quasimonotone algorithms for tracer advection. The model is being equipped with unified surface and bottom boundary layer models, based on the KPP [17] and [18] algorithms, offering simultaneous treatment of surface forcing and wave and sediment transport effects on bottom friction. The ocean forecasts have been forced with standard products from the Navy operational regional atmospheric prediction systems (NORAPS) and the Global atmospheric prediction systems (NOGAPS) and the Regional Atmospheric Modeling Systems (RAMS). Assimilated data include satellite SST and CODAR surface currents via optimal

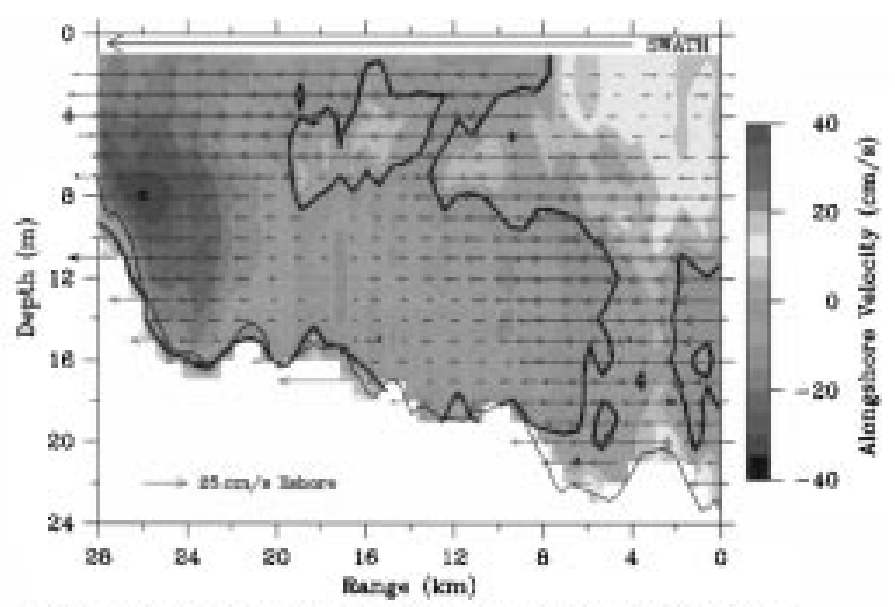

Surface Tewed-ADCP Velocity Section: Dete 980723, Lez 03

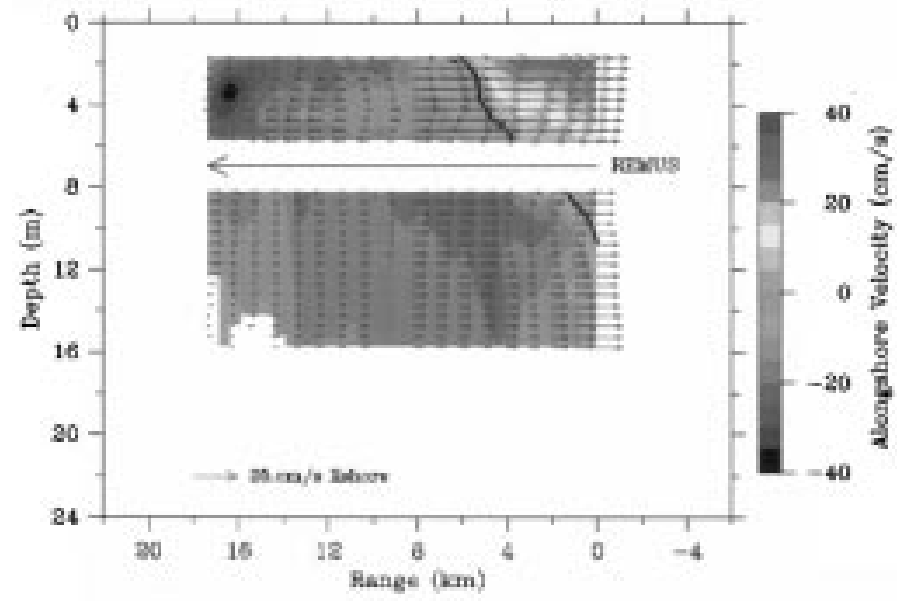

FEXUS ADCP Velocity Section. Date 980 ras

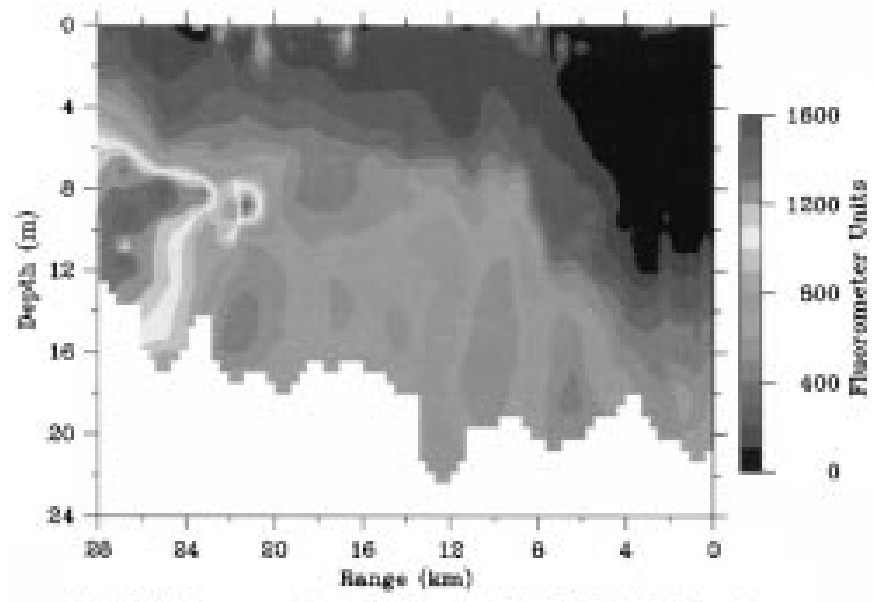

MiniBat Fuorometer Section: Date 980723, Leg 3

Fig. 5. Water column data collected during an upwelling event on 23 July, 1998. The upwelling centers at LEO are centered in a low-pressure region of an alongshore pressure gradient. This gradient produces a subsurface southward flowing 'jet' of water seen here in the detided alongshelf velocity, measured both by (a) surface towed ADCP and (b) REMUS ADCP. (c) Associated with this jet of water are high optical loads dominated by phytoplankton indicated here by high fluorescence signals onshore in the southward flowing alongshore jet.

interpolation (OI) and nudging, respectively. With the available meteorological inputs and turbulent closure schemes [17], [19], 


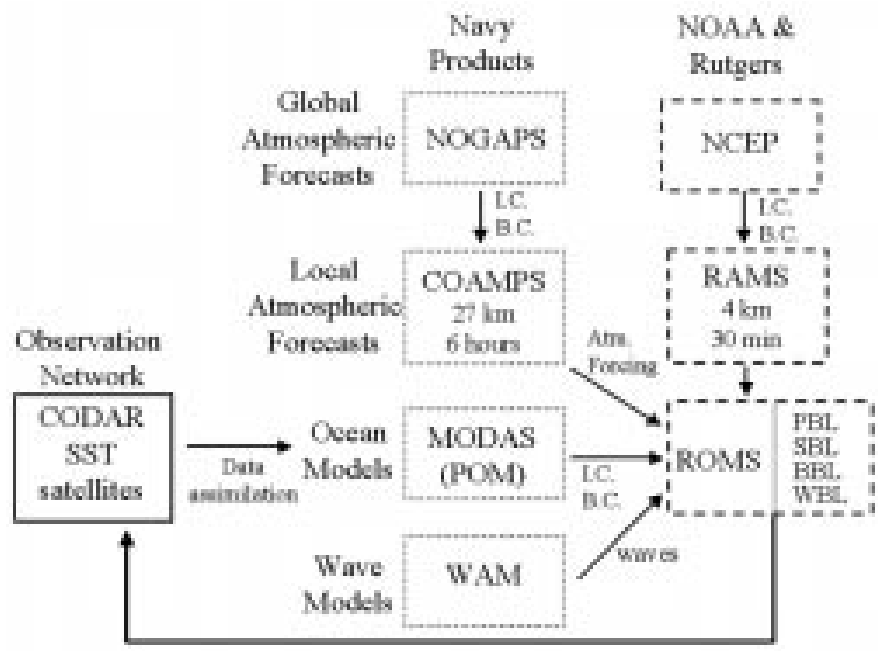

Fig. 6. Schematic for the ocean nowcast/forecast modeling system and the relationship to the weather forecast models and the in situ observation network.

[20] ensemble forecasts are run and the outputs can then be compared to the available real-time data. In this observationally rich environment, forecast errors are dominated by uncertainties in the model physics or future boundary conditions rather than initial conditions. Therefore, ensemble forecasts with differing model parameterizations provide a unique opportunity for model refinement and validation.

The ROMS circulation model continues to be advanced and will be coupled to an optically-based ecosystem food web model. The Ecological Simulation (EcoSim) 1.0 model is being modified for use in coastal waters. The model has simulated the seasonal succession of phytoplankton communities and changes in the optical properties in the Sargasso Sea [21], [22]. This model describes the temporal changes in the in situ optical constituents and the impact on water clarity and resulting feedbacks on the ecosystem. EcoSim utilizes the spectral distribution of light energy, along with temperature and nutrients, to drive the growth of phytoplankton functional groups (FG) representing broad classes of the phytoplankton species. The advantage of such of a modeling approach is that the model is initialized using the observational data stream from the optical instruments.

Centralized Control Center (COOLROOM): A critical aspect to the operation of an observatory is having one centralized location to receive, process and visualize the real-time data and then disseminate the information to scientists on ships, aircrafts or to modelers for assimilation. This command control structure is analogous to NASA control rooms or military command centers. The first goal is to disseminate data rapidly to the research fleet to optimize ship and AUV sampling patterns. Secondarily, the goal is to provide open access to all available qualitycontrolled data. To facilitate dissemination of data the Rutgers ocean data access network (RODAN) has been developed. The goal is to provide simple access to the LEO-15 datasets to a wide range of users in both the scientific community and the general public.

RODAN is operated by a web server that has access to several databases and the associated meta-data, analysis modules (usually written in Matlab, C or Fortran) and Visualization soft-

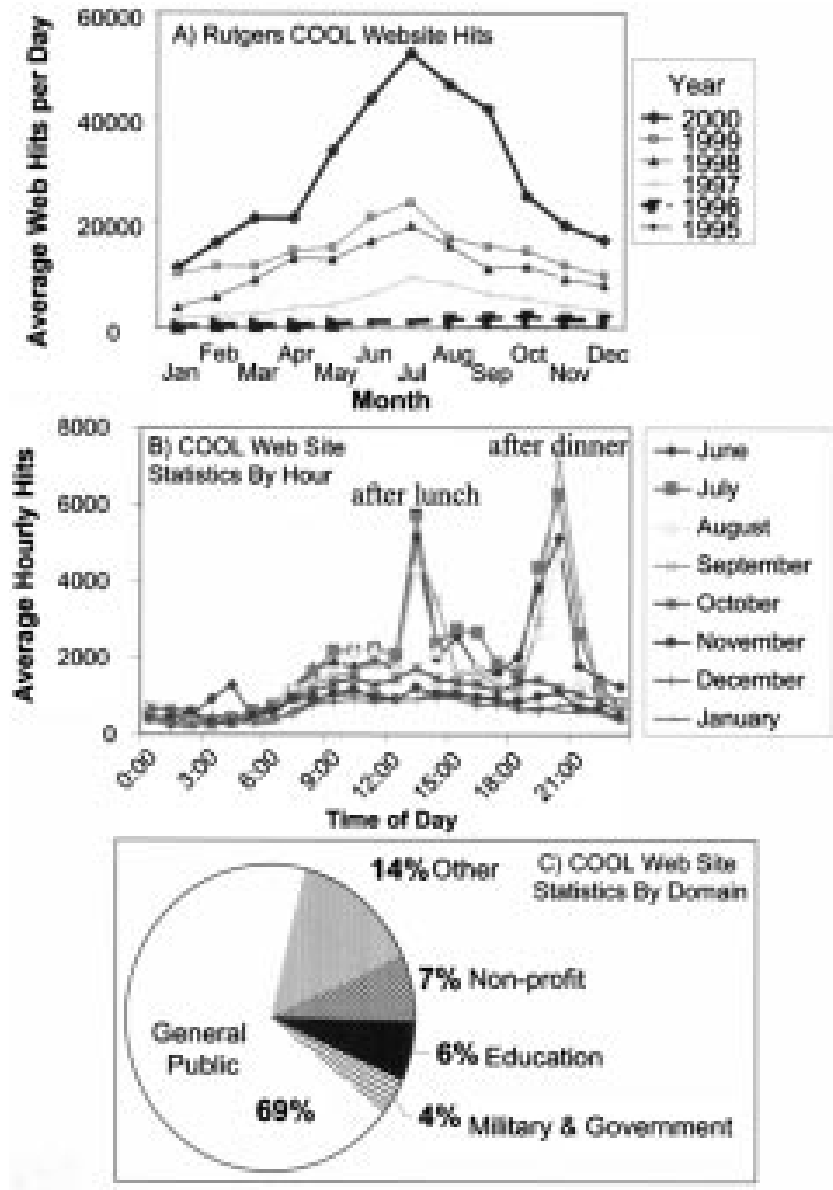

Fig. 7. Web statistics for the COOLROOM website. (a) The average web hits per day as a function of month over the last six years. Web hits for 2001 continue the upward swing into the year 2001. (b) Web activity variability as a function of the time of day that illustrates pronounced web activity after lunch and dinner. (c) The web statistics based on web domain name with the general public being the largest user of the web site.

ware (Matlab or Java Applet). The Web interfaces on the virtual controller for RODAN are written in Java, C and Perl. When you access the site from the Web, a GUI will appear on your screen that explains what data are available, provides access to the metadata and asks for information on your specific request (e.g., time periods of interest, processes to be run, do you want to plot the data, or download ascii files). The virtual controller will access and process the data using the available analysis modules. If a plot is requested, the controller will plot the data and send it back to the user for display on their screen. If only datafiles are requested, they can be downloaded and stored on the user's computer. Datasets currently accessible from the Web (http://marine.rutgers.edu/cool/rodan.html) include the underwater node data, the meteorological data, the CODAR data, moored/towed/AUV ADCP data and, declouded AVHRR sea surface temperature data. By Fall 2001, ship bio-optical data will be available.

In addition to the scientific community, real-time data are distributed to the general public via the world-wide-web. The coastal ocean observation lab (COOL) designed a user friendly web site for the general population in order to facilitate nonscientists to access and understand a suite (CODAR, Remote Sensing) of data products (www.thecoolroom.org). Interest has 
grown progressively each year and the site averaged over 50000 hits/day during the summer months of 2000 [Fig. 7(a)]. Recently during the spring of 2001, large market (New York and Philadelphia) television newscasts ( $\mathrm{NBC}$ and $\mathrm{ABC}$ ) have been using the COOLROOM website in nightly evening weather broadcasts. Web hits have since surged up to 125000 web hits per day. Interestingly, use of the website tracks human diurnal social patterns [Fig. 7(b)] with the majority of the hits occurring after lunch and dinner. Historically, close to $70 \%$ of the web hits have been the general public as opposed to academic, military, or government users [Fig. 7(c)].

\section{CASE EXAmples Using The LEO AsSeTS}

Upwelling: The largest variations in ocean temperatures along the New Jersey coast, other than seasonal, are caused by episodic summertime upwelling events driven by southwesterly winds associated with the Bermuda High. Off the southern coast of New Jersey, topographic variations associated with ancient river deltas cause upwelled water to evolve into an alongshore line of recurrent upwelling centers that are co-located with historical regions of low dissolved oxygen. A focus of the CPE efforts was to determine if upwelling resulted in significantly higher organic carbon loads and what was the nature of this organic material. The initiation phase of upwelling was predicted by the ROMS and was used to organize the sampling transect patterns. Sampling strategies were also adjusted based on the real-time satellite and node data, both of which clearly indicated the timing and spatial extent of the upwelling. Associated with the upwelling was an immediate increase in water column turbidity, which was sufficient to overwhelm optical features that dominated the variability in the inherent optical properties prior to the upwelling [Figs. 1(c) and 4 (a) and (b)]. The enhanced turbidity is correlated with an increase in phytoplankton [Fig. 4(b)]. The surface flow field consists of a cyclonic eddy within the cold upwelling center and a northward flowing surface jet on the warm side of the upwelling front that makes a sharp anticyclonic turn around the cold center. A ship-towed SWATH $\mathrm{ADCP}$ and an undulating CTD/Fluorometer were sent to patrol just north of the eddy center and a REMUS Survey Vehicle was sent to patrol the transect just south. Subsurface current observations acquired by both the Survey REMUS and the towed SWATH vehicles on the cross-shelf transects [Fig. 5(a) and (b)] not only indicate that the northward-flowing upwelling jet on the offshore side is confined to the upper water column above the thermocline, it also reveals a previously undetected southward-flowing, subsurface jet on the nearshore side below the thermocline. The corresponding fluorometer section [Fig. 5(c)] indicates that the highest phytoplankton concentrations of the season were located within the subsurface jet, leading to the hypothesis that increases in phytoplankton concentration within the upwelling center are dominated by advective loading from the north.

This physical data was processed in real time and used to direct a bio-optical survey vessel studying the same upwelling centers. The optical features of the upwelled waters were often dominated by inorganic particles, as indicated by high scattering coefficients, during the earliest phases of the upwelling cycle, but particulate organic carbon (POC) rapidly became the dominant optical constituent $\left(R^{2}=0.88\right.$ between absorption at $650 \mathrm{~nm}$ and POC). The POC is strongly associated with the accessory carotenoid fucoxanthin in 1998 indicating the importance of diatoms and the particulate carbon:nitrogen ratios are consistent with that of healthy phytoplankton. During the 1999 field season, diatoms and dinoflagellates dominated the phytoplankton communities in the nearshore coastal jet. Offshore waters were dominated by cyanobacteria and Prochlorococcus.

Biological Slicks: One focus of the summer 2000 field efforts was to find and characterize the dynamics of small-scale (1-100 m) optically-significant features that would be visible in high resolution ocean color imagery. Weekly planning relied on dynamical forecasts generated through the ROM's model, which at the time of the 2000 experiment suggested there would be a persistent southward flowing nearshore jet. These forecasts and the most recent CODAR fields assisted the physical survey vessel in deciding what survey lines should be occupied.

Initial CODAR fields suggested convergence zones would be located on the offshore side of the southern portion of our study space [Fig. 2(a)]; however in the time that the ships had adjusted their location and steamed into position, it was observed that the currents had reversed [Fig. 2(b)]. The net result was that the convergence zone was no longer present due to the tidal reversal. By the time ships were on location the once onshore tidal flow had reversed leading to the dispersion of biological material.

Short-term statistical current forecasts were constructed by decomposing the CODAR currents into tidal and nontidal components, moving the tidal component forward in time and persisting either the latest nontidal currents or the trend in the latest nontidal currents. Short-term (several hours) forecasts of this type were then used to adjust the position and timing of the optical boats looking for the convergence zones. These turbid features reappeared on the subsequent tidal reversal once again leading to an accumulation of material in a convergence zone. The highly turbid water on the inshore side of the convergence was associated with the southward flowing jet of low saline water. The low saline water largely resulted from terresterial washout in response to the heavy rainfall in the Mid-Atlantic region. The turbidity was associated with high phytoplankton stocks and high scattering reflecting the significant presence of nonbiogenic particles. Despite the high turbidity, bioluminescent loads were very low in these low saline waters. The bioluminescence potential was significantly higher in the offshore waters beyond the low saline water. The bioluminescence was associated with the red-tide dinoflagellate Ceratium fusus. Characterization of this bioluminescence front was critically dependent on the short-term forecasts, which indicated the presence of the convergence zone. Success in defining this dynamic feature would have been limited using traditional sampling strategies on a single ship.

\section{EXPANSION TO A NATIONAL COASTAL OBSERVATORY}

The expanding network of observatories will serve a suite of applied and scientific needs. Real-time data will be used by both the general public and the regulatory agencies charged 
with the management of coastal resources. Currently, the proposed observatories will study a suite of physical, chemical and biological oceanographic questions; however beyond this each observatory has its own unique flavor for studying specific scientific questions of the research groups constructing them. For example, while LEO is specialized for studying the physical forcing of planktonic food webs in the nearshore coastal ocean, NEPTUNE on the Juan de Fuca Ridge will be capable of studying a variety of plate-scale processes [23], while the WHOI Katama observatory is optimally designed for questions related to air-sea interactions during storm events. Despite the individual flavor of each observatory, these high-resolution regional sites will be unified through a coherent suite of broadband measurements.

We propose that regional observatories be linked through remote sensing, mooring and AUV technologies. Satellite remote sensing will provide a suite of measurements including sea surface temperature, biological productivity, currents, sediments, ice-cover and sea surface roughness. These surface maps would complement a contiguous network of long-range surface current radar systems providing surface currents (speed and direction) and suite of derived products such as divergence, convergence and vorticity. These surface maps will be complemented with in situ data collected by moorings and AUVs. Two classes of moorings will be central to national network. Fixed-location moorings will be an important component to the high-resolution regional observatories. These buoys will be complemented by new generation, low-cost, relocatable systems being developed by several research groups. Finally, we propose that the observational network will be completed with fleets of AUVs patrolling offshore filling the data "gaps" between the regional observatories. The SLOCUM gliders show much promise as they have an extended deployment period (days to months) and provide near real-time horizontal and vertical data. The relatively low purchase price of the gliders makes them a cost effective enabling technology.

While many of the in situ systems (moored and AUVs) have matured rapidly over the last five years, research is now focusing on maintaining an effective year-round presence in the ocean. Currently at LEO, the efforts have concentrated on month long efforts, which allows biofouling and sensor degradation considerations to be largely ignored. This will not be the case in transitioning efforts at LEO to year round operation. Another obstacle is that many of the AUVs are power limited, which minimizes their presence in the ocean. Technical solutions tested at LEO have focused on low-power AUVs (i.e., gliders) or in situ docking stations that provide power to recharge AUVs. Both approaches show promise and will be refined in the coming years. Finally, significant effort at LEO will be directed on developing effective strategies for maintaining a robust and effective maintenance schedule that minimizes the "down" time of the systems but also assures that quality data are not compromised by biofouling. These considerations vary with sensor, with the optical and chemical sensors being the most sesitive to biofouling. Thus developing operational observatories will require more than just buying and deploying a diverse suite of sensors as the success of an observatory will be its ability to maintain a continual window into the ocean interior over seasonal scales.
In conclusion, the recent development of remote sensing technology, surface current radar and AUV technology make the development of a national observatory a possibility. The proposed network will unite the expanding list of regional observatories. The national network combined with the regional ocean observatories will provide a nested observation grid providing boundary conditions for regional process studies, data over biogeochemically relevant scales, information aiding water quality managers and coast guard authorities and a data stream that will be of wide public interest.

\section{ACKNOWLEDGMENT}

The development of LEO is only possible through the concerted research efforts of numerous collaborating research institutions including federal (NAVAIR, NOAA-NESDIS, NRL, NUWC), academic (WHOI, APL, Cornell, Dalhousie, Lamont Doherty, Mote Marine Labs, OSU, Scripps, UCSB) and corporate partners (CODAR, Satlantic, SeaSpace, HOBI Inc., Webb Inc.). The spirit of a "sea-going mash unit" present at LEO is a reflection of those fun and supportive collaborations. Finally, success at LEO reflects the stellar students and support staff at Rutgers and the ongoing support from the great state of New Jersey.

\section{REFERENCES}

[1] P. M. Holligan and W. A. Reiners, "Predicting the responses of the coastal zone to global change," Adv. Ecol. Res., vol. 22, no. 2, pp. 211-221, 1992.

[2] P. E. Biscaye, C. N. Flagg, and P. G. Falkowski, "The shelf edge exchange experiment, SEEP-II: An introduction to hypotheses, results and conclusions," Deep-Sea Res., vol. 41, no. 2, pp. 231-253, 1994.

[3] P. G. Falkowski, P. E. Biscaye, and C. Sancetta, "The lateral flux of biogenic particles from the eastern North American continetal margin to the North Atlantic Ocean,” Deep-Sea Res., vol. 41, no. 2, pp. 583-602, 1994.

[4] G. M. Hallengraeff, "A review of harmful algal blooms an their apparent global increase," Phycologia, vol. 32, pp. 79-99, 1993.

[5] D. Roemmich and J. McGowan, "Climatic warming and the decline of zooplankton in the California current," Science, vol. 267, no. 5209, pp. $1324-1326,1995$.

[6] D. M. Karl and R. Lukas, "The Hawaii Ocean Time-series (HOT) program: Background, rationale and field implementation," Deep-Sea Res., vol. 43, no. 2, pp. 129-156, 1996.

[7] A. F. Michaels, A. H. Knap, R. L. Dow, K. Gundersen, R. J. Johnson, J. Sorensen, A. Close, G. A. Knauer, S. E. Lohrenz, V. A. Asper, M. Tuel, and R. R. Bidigare, "Seasonal patterns of ocean biogeochemistry at the U.S.JGOFS Bermuda Atlantic time-series study site," Deep-Sea Res. vol. 41, no. 3, pp. 1013-1038, 1994.

[8] R. S. Smith, O. B. Brown, F. E. Hoge, K. S. Baker, R. H. Evans, R. N. Swift, and W. E. Esaias, "Multiplatform sampling (ship, aircraft and satellite) of a Gulf stream warm core ring," Appl. Opt., vol. 26, no. 14, pp. 2068-2081, 1987.

[9] T. Dickey, "Sensors and systems for sampling/measuring ocean processes extending over nine orders of magnitude," Sea Tech., vol. 34, no. 8, pp. 47-55, 1993.

[10] O. Schofield, J. Gryzmski, W. P. Bissett, G. Kirkpatrick, D. F. Millie, M A. Moline, and C. Roesler, "Optical monitoring and forecasting systems for harmful algal blooms: Possibility or pipedream?," J. Phycol., vol. 35, no. 6, pp. 125-145, 1999 .

[11] S. M. Glenn, T. D. Dickey, B. Parker, and W. Boicourt, "Operational observation networks for ports, a large estuary and an open shelf," Oceanogr., vol. 13, no. 1, pp. 12-23, 2000.

[12] - "Long-term real-time coastal ocean observation networks," Oceanogr., vol. 13, no. 1, pp. 24-34, 2000.

[13] D. B. Haidvogel, J. Blanton, J. C. Kindle, and D. R. Lynch, "Coastal ocean modeling: Processes and real-time systems," Oceanogr., vol. 13, no. 1, pp. 35-46, 2000. 
[14] D. E. Barrick and B. J. Lipa, "Evolution of bearing determination in HF current mapping radars," Oceanogr., vol. 10, no. 2, pp. 72-75, 1997.

[15] C. von Alt, B. Allen, T. Austin, and R. Stokey, "Remote environmental measuring units," in Proc. Symp. Autonomous Underwater Vehicle Technology, 1994, pp. 13-19.

[16] P. Simonetti, "Low-cost, endurance ocean profiler," Sea Tech., vol. 38, no. 1, pp. 17-21, 1998.

[17] W. G. Large, J. C. McWilliams, and S. C. Doney, "Oceanic vertical mixing: A review and a model with a nonlocal boundary layer parameterization," Rev. Geophys., vol. 32, no. 4, pp. 363-403, 1994.

[18] R. Styles and S. M. Glenn, "Modeling stratified combined wave-current bottom boundary layers," J. Geophys. Res., no. 10, pp. 119-124, 2000.

[19] G. L. Mellor and T. Yamada, "Development of turbulent closure model for geophysical fluid problems," Geophys. and Space Phys., vol. 20, pp. $851-875,1982$

[20] J. F. Price, R. A. Weller, and R. Pinkel, "Diurnal cycling: Observations and models of the upper ocean responses to diurnal heating, cooling and wind-mixing," J. Geophys. Res., vol. 91, no. 9, pp. 8411-8427, 1986.

[21] W. P. Bissett, J. J. Walsh, D. A. Dieterle, and K. L. Carder, "Carbon cycling in the upper waters of the Sargasso Sea: I. Numerical simulation of differential carbon and nitrogen fluxes," Deep-Sea Res., vol. 46, no. 2, pp. 205-269, 1999

[22] W. P. Bissett, K. L. Carder, J. J. Walsh, and D. A. Dieterle, "Carbon cycling in the upper waters of the Sargasso Sea II. Numerical simulation of the apparent and inherent optical properties," Deep-Sea Res., vol. 46, no. 2, pp. 271-317, 1999.

[23] J. R. Delaney, G. R. Heath, B. Howe, A. D. Chave, and H. Kirkham, "NEPTUNE: Real-time ocean and earth sciences at the scale of a tectonic plate," Oceanogr., vol. 13, no. 2, pp. 71-79, 2000.

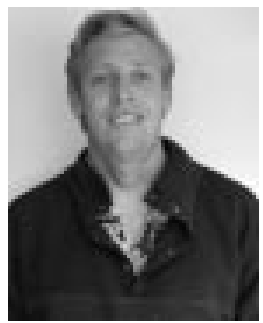

Oscar Schofield received the B.A. and Ph.D. degrees in biology from the University of California at Santa Barbara.

$\mathrm{He}$ is an Associate Professor at the the Institute of Marine and Coastal Sciences, Rutgers University, New Brunswick, NJ, where he has been for the past five years. He co-founded the Coastal Ocean Observation Laboratory (COOL) with Dr. S. Glenn during a hangover-dominated bus ride somewhere in New Mexico. His interests include the physiological ecology of phytoplankton, environmental forcing of eucaryotic evolution, walks on the beach, physical-biological interactions and hydrological optics.

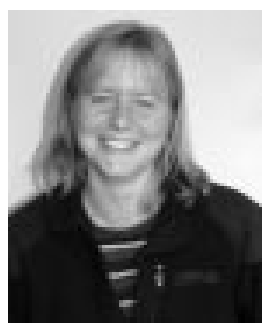

Trisha Bergmann received the B.S. degree in environmental science from the Rutgers University, New Brunswick, NJ, in 1996, and currently is working toward the Ph.D. degree at the Institute of Marine and Coastal Sciences at the same university.

Her research interests include hydrological optics, the physiological ecology of phytoplankton, ocean color remote sensing and the quantum efficiency of phycobilin-pigment light-harvesting complexes.

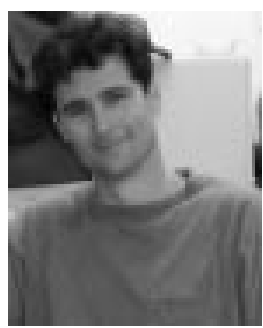

Paul Bissett received the B.S. degree in finance and economics from the University of Florida, Gainesville, and the Masters and Ph.D. degrees in marine science from the University of South Florida, Tampa.

$\mathrm{He}$ founded and currently is the Director of the Florida Environmental Research Institute, Tampa. His research interests include ecosystem analysis/simulation/prediction, bio-optical algorithm development and predictive hydrological optics.

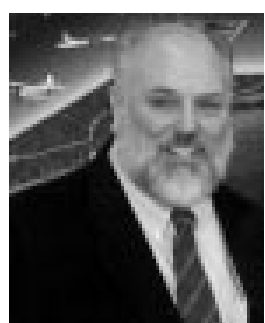

J. Frederick Grassle is a Professor of marine and coastal sciences and Director of the Institute of Marine and Coastal Sciences (IMCS) at the Rutgers University, New Brunswick, NJ, for the past ten years. His research interests include the study of the continental shelf, slope and rise communities, coastal ecosystem monitoring and interdisciplinary studies of pollutant fate and effects.

Dale B. Haidvogel is a Professor II at the Institute of Marine and Coastal Sciences, Rutgers University, New Brunswick, NJ, for the past nine years. Ocean circulation models developed by his Ocean Modeling Group have been supplied to approximately 150 scientists worldwide for physical oceanographic and interdisciplinary modeling applications. His research interests include the development, comparison, and validation of regional and global-scale ocean circulation models and applications to coastal dynamics and coastal/deep ocean exchange.

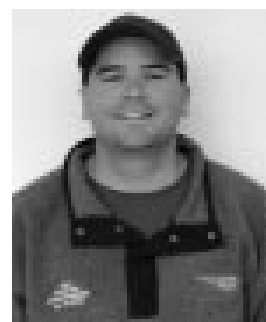

Josh Kohut received the B.S. degree in physics from the University of Charleston, Charleston, WV, and is working toward the Ph.D. degree at the Institute of Marine and Coastal Sciences at Rutgers University, New Brunswick, NJ.

His research interests include the development and optimization of surface-current radar technologies, beers, the dynamical behavior of convergence/divergence zones and wave current-interactions in nearshore coastal waters.

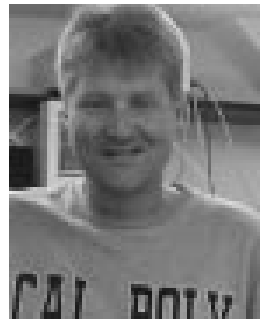

Mark Moline is an Assistant Professor in the Department of Biology at the California Polytechnic State University for the last two years. He has initiated a research program on phytoplankton community dynamics in coastal/estuarine waters and recently received both NASA and ONR Young Investigator Program awards. His research efforts have focused on bioluminescence, autonomonous underwater vehicles, the community ecology of aquatic ecosystems, developing class-specific chemotaxonomic markers for phytoplankton and relating these measurements to in

situ optical signatures.

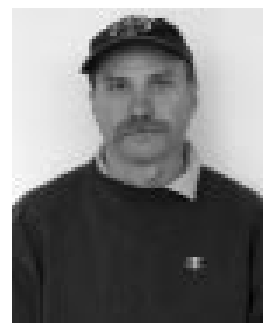

Scott M. Glenn is a Professor at the Institute of Marine and Coastal Sciences, Rutgers University, New Brunswick, NJ, for the past nine years. He has led numerous multiinstitutional interdisciplinary field programs at LEO-15 since 1993. He co-founded the Coastal Ocean Observation Laboratory with Dr. $\mathrm{O}$. Schofield during a hangover-dominated bus ride somewhere in New Mexico. His research interests include the development of multi-platform observation systems to provide assimilation datasets for numerical models, the evaluation and improvement of numerical models through model/data comparisons and the use of real-time data and coupled atmospheric/ocean forecasts for adaptive sampling of ocean phenomena. 